\title{
GABAergic Synaptic Scaling in Embryonic Motoneurons Is Mediated by a Shift in the Chloride Reversal Potential
}

\author{
Carlos Gonzalez-Islas, ${ }^{1}$ Nikolai Chub, ${ }^{2}$ Miguel Angel Garcia-Bereguiain, ${ }^{1}$ and Peter Wenner ${ }^{1}$ \\ ${ }^{1}$ Department of Physiology, School of Medicine, Emory University, Atlanta, Georgia 30322, and ${ }^{2}$ Developmental Neurobiology Section, National Institute of \\ Neurological Disorders and Stroke, National Institutes of Health, Bethesda, Maryland 20892-3721
}

\begin{abstract}
Homeostatic synaptic plasticity ensures that networks maintain specific levels of activity by regulating synaptic strength in a compensatory manner. When spontaneous network activity was blocked in vivo in the embryonic spinal cord, compensatory increases in excitatory GABAergic synaptic inputs were observed. This homeostatic synaptic strengthening was observed as an increase in the amplitude of GABAergic miniature postsynaptic currents. We find that this process is mediated by an increase in chloride accumulation, which produces a depolarizing shift in the GABAergic reversal potential $\left(E_{\mathrm{GABA}}\right)$. The findings demonstrate a previously unrecognized mechanism underlying homeostatic synaptic scaling. Similar shifts in $E_{\mathrm{GABA}}$ have been described following various forms of neuronal injury, introducing the possibility that these shifts in $E_{\mathrm{GABA}}$ represent a homeostatic response.
\end{abstract}

\section{Introduction}

Homeostatic synaptic plasticity is the process of homeostatically maintaining network activity levels through compensatory adjustments in synaptic strength (Rich and Wenner, 2007; Turrigiano, 2008). For example, when network activity was blocked in cultured neural networks for days, increases in the amplitude of excitatory miniature postsynaptic currents (mPSCs) and decreases in the amplitude of inhibitory GABAergic mPSCs were observed (Turrigiano et al., 1998; Kilman et al., 2002). The compensatory changes in mPSC amplitude were observed throughout the distribution of amplitudes [synaptic scaling (Turrigiano et al., 1998)]. The mechanisms that underlie compensatory changes in excitatory and inhibitory quantal amplitude following activity blockade of cultured networks include changes in postsynaptic receptor number and the amount of transmitter released per vesicle (Wilson et al., 2005; Rich and Wenner, 2007; Turrigiano, 2008). Mechanisms underlying synaptic scaling following activity perturbations in vivo are poorly understood.

We have recently identified homeostatic synaptic scaling in the embryonic network (Gonzalez-Islas and Wenner, 2006). Spontaneous network activity (SNA) is observed in virtually all developing circuits, and is thought to be important for the maturation of the synaptic networks in which it is expressed (O'Donovan, 1999; Ben-Ari, 2001; Zhang and Poo, 2001). In the spinal cord, SNA occurs as episodes of activity experienced in most cells, followed by longer-duration periods of inactivity (O’Donovan et al., 1998). Spinal SNA, observed through embry-

Received March 29, 2010; revised May 25, 2010; accepted June 2, 2010.

This research was supported by National Institute of Neurological Disorders and Stroke Grant NS046510 and National Science Foundation Grant 0616097 to P.W. and by the Intramural Program of the National Institutes of Neurological Disorders and Stroke. We thank Drs. Michael O'Donovan and Mark Rich for their comments on the manuscript, and Dr. Porfirio Nava for assistance with Western blots.

Correspondence should be addressed to Peter Wenner, Department of Physiology, Room 601, Whitehead Building, School of Medicine, Emory University, Atlanta, GA 30322. E-mail: pwenner@emory.edu.

DOI:10.1523/JNEUROSCI.1659-10.2010

Copyright $\odot 2010$ the authors $\quad 0270-6474 / 10 / 3013016-05 \$ 15.00 / 0$ onic movements, was blocked in the chick embryo in ovo, which resulted in GABAergic synaptic scaling in motoneurons. An increase in $\mathrm{GABA}_{\mathrm{A}} \mathrm{mPSC}$ amplitude was compensatory because of the depolarizing nature of GABA at this stage of development (Gonzalez-Islas and Wenner, 2006). In the current study, we demonstrate an increase in the driving force for GABAergic currents, but find no evidence for an increase in postsynaptic $\mathrm{GABA}_{\mathrm{A}}$ receptors or vesicle content of GABA. This change in GABAergic reversal potential $\left(E_{\mathrm{GABA}}\right)$ was mediated by an increase in chloride accumulation.

\section{Materials and Methods}

Dissection. Stage 36 (Hamburger and Hamilton, 1951) chick embryo spinal cords, with attached muscle nerves, were dissected under cooled $\left(15^{\circ} \mathrm{C}\right)$ Tyrode's solution containing the following (in mM): $139 \mathrm{NaCl}, 12$ D-glucose, $17 \mathrm{NaHCO}_{3}, 3 \mathrm{KCl}, 1 \mathrm{MgCl}_{2}$, and $3 \mathrm{CaCl}_{2}$ [for a full description, see Gonzalez-Islas and Wenner (2006)]. After the dissection, the cord was allowed to recover for at least $6 \mathrm{~h}$ in Tyrode's at $18^{\circ} \mathrm{C}$. The cord was then transferred to a recording chamber and continuously perfused with Tyrode's solution that was heated to $28^{\circ} \mathrm{C}$.

$m P S C$ recordings. Whole-cell patch-clamp recordings were made from ventral horn motoneurons localized between the lumbosacral segments 1 and 3 to acquire mPSCs, as described previously (Gonzalez-Islas et al., 2009). Briefly, whole-cell recordings (electrodes, 5-10 M $\Omega$ ) were obtained from antidromically identified motoneurons. Recordings were terminated whenever significant increases in input resistance $(>20 \%)$ occurred. Standard extracellular recording solution for mPSCs contained the following (in mM): $\mathrm{NaCl}, 139 ; \mathrm{KCl}, 5 ; \mathrm{NaHCO}_{3}, 17 ; \mathrm{CaCl}_{2}, 3$; $\mathrm{MgCl}_{2}$, 1; D-glucose, 12; TEA, 30; CsCl, 5; TTX, 0.001. Glutamatergic antagonists CNQX $(10 \mu \mathrm{M})$ and AP-5 $(50 \mu \mathrm{M})$ were added to the bath to isolate GABAergic mPSCs. The intracellular patch solution for GABA mPSC recordings contained the following (in $\mathrm{mm}$ ): $5 \mathrm{NaCl}, 100$ K-gluconate, $30 \mathrm{KCl}, 5 \mathrm{CsCl}, 10 \mathrm{TEA}-\mathrm{Cl}, 10 \mathrm{HEPES}, 10 \mathrm{BAPTA}, 1 \mathrm{MgCl}_{2}$, $0.1 \mathrm{CaCl}_{2}, 1 \mathrm{Na}_{2} \mathrm{ATP}, 0.1 \mathrm{MgGTP}, 10 \mathrm{QX}-314$, and 0.1 verapamil; $\mathrm{pH}$ was adjusted to 7.3 with $\mathrm{KOH}$. Pipette solution osmolarity was between 280 and $300 \mathrm{mOsm}$. Junction potentials were corrected online. Currents were filtered on-line at $5 \mathrm{kHz}$, digitized at $10 \mathrm{kHz}$, and analyzed using Minianalysis software (Synaptosoft). 
A

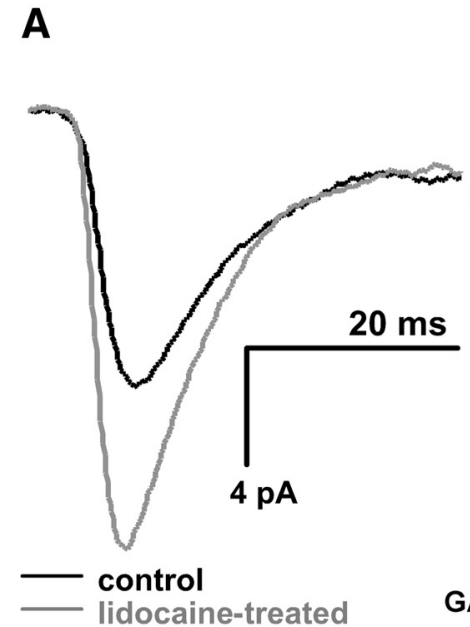

B

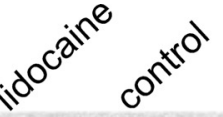

$\mathrm{GABA}_{\mathrm{A}} \alpha$

Actin

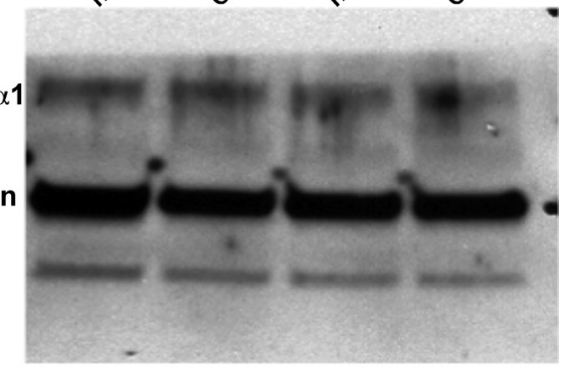

$\mathrm{GABA}_{A} \beta 2 / 3$
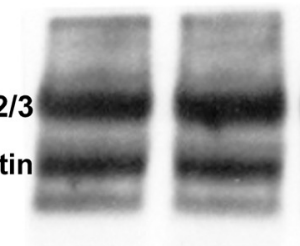

Figure 1. Activity-blocked motoneurons have increased GABAergic mPSC amplitude that do not appear to be mediated by changes in total protein levels of $\mathrm{GABA}_{A}$ subunits. $A, G A B A_{A} \mathrm{mPSC}$ amplitude was increased in activity-blocked motoneurons compared to controls, as shown in the averaged trace. $\boldsymbol{B}$, Western blots from control and activity-blocked ventral spinal cords demonstrate no difference in total protein of either $\alpha 1$ or $\beta 2 / 3 \mathrm{GABA}_{\mathrm{A}}$ subunits (normalized to actin protein levels).

For experiments in $0 \mathrm{~mm} \mathrm{HCO}_{3}^{-}, I_{\mathrm{mPSC}}-V$ data were collected in standard extracellular solution, then the solution was changed to a $0 \mathrm{~mm}$ $\mathrm{HCO}_{3}^{-}$extracellular solution, in which $\mathrm{NaHCO}_{3}$ was substituted by 17 mM Na-gluconate and 10 mm HEPES; $\mathrm{pH}$ adjusted to 7.3 with $\mathrm{NaOH}$. Additionally the $0 \mathrm{~mm} \mathrm{HCO}_{3}^{-}$solution was bubbled with $100 \% \mathrm{O}_{2}$. Pipette solution was (in mM) $5 \mathrm{Na}$-gluconate, $130 \mathrm{~K}$-gluconate, $5 \mathrm{CsCl}$, 10 TEA-Cl, 10 HEPES, 10 BAPTA, $1 \mathrm{MgCl}_{2}, 0.1 \mathrm{CaCl}_{2}, 1 \mathrm{Na}_{2} \mathrm{ATP}, 0.1$ MgGTP, 10 QX-314, and 0.1 verapamil; $\mathrm{pH}$ was adjusted to 7.3 with $\mathrm{KOH}$.

Chloride leak recordings. For recording chloride leak conductances, we used the following external solution (in mM): $110 \mathrm{NaCl}, 29 \mathrm{Na}$-gluconate, $17 \mathrm{NaHCO}_{3}, 3 \mathrm{CaCl}_{2}, 1 \mathrm{MgCl}_{2}, 12$ D-glucose, $30 \mathrm{TEA}-\mathrm{Cl}, 5 \mathrm{CsCl}, 0.4$ $\mathrm{CdCl}_{2}$, 5 4-AP, $0.01 \mathrm{CNQX}, 0.05 \mathrm{APV}$, and 0.001 TTX. Pipette solution contained the following (in mM): $146 \mathrm{CsCl}, 10$ HEPES, $5 \mathrm{EGTA}, 2 \mathrm{MgCl}_{2}$, $0.1 \mathrm{CaCl}_{2}, 1 \mathrm{Na}_{2} \mathrm{ATP}, 0.5 \mathrm{MgGTP}, 10 \mathrm{QX}-314$, and 0.1 verapamil; $\mathrm{pH}$ was adjusted to 7.3 with $\mathrm{CsOH}$. The stimulus protocol used to elicit this conductance, consisted of a voltage ramp from the holding potential of 0 $\mathrm{mV}$ to $-90 \mathrm{mV}$, at a rate of $0.18 \mathrm{mV} / \mathrm{ms}$.

Perforated patch recordings. Pipette solution for gramicidin perforated patch measurements contained the following (in $\mathrm{mm}$ ): $140 \mathrm{~K}$-gluconate, $10 \mathrm{NaCl}, 10$ HEPES, and 30 sucrose; $\mathrm{pH}$ was adjusted to 7.2 with $\mathrm{NaOH}$ [detailed methods provided by Chub and O'Donovan (2001)]. Gramicidin (from Bacillus brevis, Sigma-Aldrich) was added to pipette solution (final concentration $50 \mathrm{mg} / \mathrm{ml}$ ). Seal and patch perforation took $30-50$ min, and was made in normal Tyrode's solution, which was then replaced with bath solution containing the following (in $\mathrm{mm}$ ): $139 \mathrm{NaCl}, 5 \mathrm{KCl}, 17$ $\mathrm{NaHCO}_{3}, 1 \mathrm{MgCl}_{2}, 12$ glucose, $0.5 \mathrm{MnCl}_{2}, 10 \mathrm{TEA}$-acetate, $5 \mathrm{CsCl}$, and 0.0005 TTX. Isoguvacine $(100 \mu \mathrm{M})$ was dissolved in modified bath solution and locally applied with a pipette by a pressure pulse (15 psi, $20-40$ s) delivered with a picospritzer (General Valve). The pipette was inserted in the ventral horn $\sim 200-400 \mu \mathrm{m}$ from the recorded neurons. Liquid junction potential $(-14.4 \mathrm{mV})$ was calculated using pClamp 9 and was corrected.

Pharmacology. At embryonic day 8 (E8), lidocaine hydrochloride aqueous solution ( $35 \mathrm{mg} / \mathrm{ml}$ plus $10 \mathrm{~mm}$ HEPES, pH 7.2) was continuously applied onto the chorioallantoic membrane of the embryos at a rate of $13.5 \mu \mathrm{l} / \mathrm{h}$, as described previously (Gonzalez-Islas and Wenner, 2006); control embryos did not receive saline injections, as no difference was observed between untreated and saline-treated embryos in this previous study. Verapamil was purchased from Calbiochem; TTX, APV, and CNQX were purchased from Tocris Cookson; $\mathrm{CsCl}$ was pur-
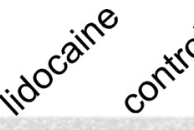
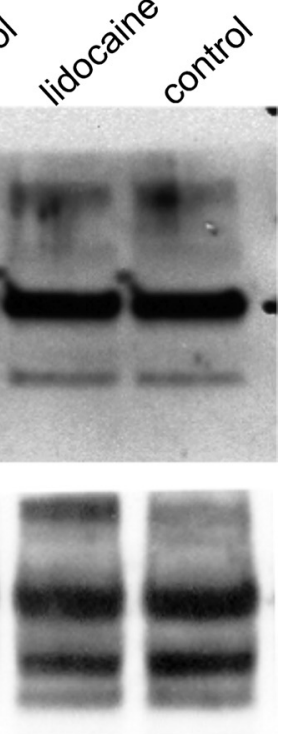

chased from Fisher Scientific; BAPTA was purchased from Fluka; HEPES from Acros Organics. All other chemicals and drugs were purchased from Sigma-Aldrich.

Immunoblot. Ventral half lumbosacral spinal cords were homogenized in RIPA buffer supplemented with protease and phosphatase inhibitors (Sigma-Aldrich). Samples were then centrifuged at $16,000 \times g$ for 5 min to remove cell debris. Protein concentration was quantitated using Bradford reagent (SigmaAldrich). Samples were separated on $4-15 \%$ SDS-PAGE, and blotted to a nitrocellulose membrane. The primary antibodies to $\mathrm{GABA}_{\mathrm{A}}$ subunits were from Millipore and diluted 1:200 (rabbit anti- $\alpha 1,06-868$, MW $51 \mathrm{kDa}$; mouse anti- $\beta 2 / 3, \mathrm{MAB} 341,55 \mathrm{kDa}$ ), and to actin (mouse anti-actin from Sigma-Aldrich, dilution 1/10,000). The secondary antibodies used were HRP-goat anti-mouse IgG (dilution 1/4000) and HRP-goat anti-rabbit IgG (dilution 1/2000) from Millipore. Primary antibodies to a receptor subunit and actin were coapplied ( 2 blots) or were applied separately (3 blots). The blot was visualized by ECL chemiluminescence (GE Healthcare). Quantitative analysis of protein expression was performed by drawing boxes around the protein bands and normalizing the signal intensity to actin intensity using Image (NIH). Blots were done 5 times, and each sample represents a lysate of 2-3 different cords.

Statistics. Data are expressed as mean \pm SE. Most statistical analysis was performed using a two-tailed Student's $t$ test (paired and unpaired) unless mentioned otherwise. GraphPad Instat software and SigmaPlot 9 were used for statistical analysis.

\section{Results}

\section{GABAergic scaling was not mediated by} increased conductance

Activity blockade triggers synaptic scaling of GABAergic mPSCs (Gonzalez-Islas and Wenner, 2006). We confirmed these results by treating chick embryos with lidocaine (blocker of voltagegated $\mathrm{Na}^{+}$channels) from E8 to E10 to block SNA. We then isolated spinal cords at E10, and obtained whole-cell recordings from antidromically identified spinal motoneurons. Consistent with previous results, we found an increase in GABAergic mPSC amplitude in activity-blocked motoneurons compared to controls (held at $-70 \mathrm{mV}-$ control $11.3 \pm 0.6 \mathrm{pA}, n=10$, lidocaine treated $17.4 \pm 0.8 \mathrm{pA}, n=13 ; p<0.0001$ ) (Fig. 1A). Several previous studies have shown that GABAergic and AMPAergic synaptic scaling were mediated by changes in postsynaptic receptor number, so we initially tested this idea by measuring protein levels for $2 \mathrm{GABA}_{\mathrm{A}}$ subunits $(\alpha 1, \beta 2 / 3)$ that were expressed in the ventral half of the spinal cord. Western blots demonstrated no difference in protein levels in control and treated cords (Fig. $1 B$ ) $(\alpha 1-n=5$ and $p=1.0, \beta 2 / 3-n=5$ and $p=0.34$, MannWhitney test). Increases in $\mathrm{GABA}_{\mathrm{A}}$ receptor function (receptor number, state of phosphorylation) or presynaptic vesicle GABA concentration would increase the conductance of the GABAergic mPSCs.

To test whether reducing activity in ovo leads to changes in $\mathrm{GABA}_{\mathrm{A}}$ mPSC conductance, we constructed $I_{\mathrm{mPSC}}-V$ plots of GABAergic mPSCs as described previously (Gonzalez-Islas et al., 2009). Voltage-gated channels and glutamatergic transmission were blocked to isolate GABAergic mPSCs, which were typically recorded in voltage steps of $10 \mathrm{mV}$ (acquire $\geq 50 \mathrm{mPSCs}, 1-2 \mathrm{~min}$ 
at each step) (Fig. 2A). We then took the average mPSC amplitude from each step and constructed $I_{\mathrm{mPSC}}-V$ plots. $\mathrm{GABA}_{\mathrm{A}}$ mPSC conductance (slope of $I_{\mathrm{mPSC}}-V$ plot) of activity-blocked motoneurons was not significantly different from controls (control $277.2 \pm 9.0 \mathrm{pS}, n=11$; lidocaine treated $296.3 \pm 13.1 \mathrm{pS}, n=16$; $p=0.29$ ) (Fig. $2 B, C$ ). The results demonstrate that increases in the function of postsynaptic receptors or vesicular GABA concentration did not mediate GABAergic scaling following in vivo activity blockade in embryonic motoneurons.

\section{GABAergic scaling was produced by a depolarizing shift in $\mathrm{GABA}_{\mathrm{A}}$ reversal potential}

$I_{\mathrm{mPSC}}-V$ plots demonstrated that $E_{\mathrm{GABA}}$ had shifted to a significantly more depolarized level $(p<0.0001)$. Average $E_{\mathrm{GABA}}$ was $-26.9 \pm 1.0 \mathrm{mV}$ for control, but $-9.9 \pm 1.1 \mathrm{mV}$ in activity-blocked motoneurons (Fig. 2B,C). This suggested that there was an increase in the driving force for these currents. We have previously shown that whole-cell electrodes with $50 \mathrm{~mm}$ chloride patch solutions (Nernst equation predicts approximately $-30 \mathrm{mV}$ ) can be used to measure $E_{\mathrm{GABA}}$ (Gonzalez-Islas et al., 2009).

To confirm these striking results, we also used perforated patch recordings to measure $E_{\mathrm{GABA}}$. We locally applied the $\mathrm{GABA}_{\mathrm{A}}$ receptor agonist, isoguvacine $(100 \mu \mathrm{M})$, in the motor column and currents were recorded in motoneurons (Fig. 3). Extracellular Tyrode's solution was in the bath with various blockers to isolate $\mathrm{GABA}_{\mathrm{A}}$ currents (see Materials and Methods). The $I-V$ plots were generated from currents recorded in response to voltage ramps made before and during isoguvacine application. The current measured before the isoguvacine puff, was then subtracted from that during the isoguvacine puff to create the $\mathrm{GABA}_{\mathrm{A}} I-V$ plot shown on the right of Figure 3, and the reversal potentials were determined [see Materials and Methods and Chub and O'Donovan (2001)]. Again, we found that $E_{\mathrm{GABA}}$ was significantly more positive in lidocaine-treated than in control motoneurons $(p=0.001)$. Mean $E_{\mathrm{GABA}}$ was $-37.9 \pm 1.0 \mathrm{mV}$ $(n=7)$ in control motoneurons versus $-15 \pm 3.1 \mathrm{mV}(n=7)$ in activity-blocked motoneurons (Fig. 3). On the other hand, the conductance of the isoguvacine-evoked currents were slightly reduced $(3.4 \pm 0.5 \mathrm{nS}$ for lidocaine-treated and $4.9 \pm 0.4 \mathrm{nS}$ for control motoneurons, $p=0.04)$. Collectively, these results demonstrate that a change in the driving force for GABA-mediated currents produced the upward scaling of GABAergic mPSCs following activity blockade.

\section{Elevated $\mathrm{Cl}_{\text {in }}^{-}$underlies the depolarized shift of $E_{\mathrm{GABA}}$}

We tested the possibility that activity-blocked motoneurons exhibit an increase in the permeability of $\mathrm{HCO}_{3}^{-}$through $\mathrm{GABA}_{\mathrm{A}}$ receptor channels, as this would lead to a depolarizing shift in $E_{\mathrm{GABA}} \cdot I_{\mathrm{mPSC}}-V$ plots were generated for activity-blocked embryos to determine $E_{\mathrm{GABA}}$ in control solution (17 $\mathrm{mM} \mathrm{HCO}_{3}^{-}$) and then following perfusion of a $0 \mathrm{~mm} \mathrm{HCO}_{3}^{-}$extracellular solution (HEPES added and bubbled with $100 \% \mathrm{O}_{2}$ ) for $20 \mathrm{~min}$ (Fig. $4 \mathrm{~A}$ ). This short-term re-

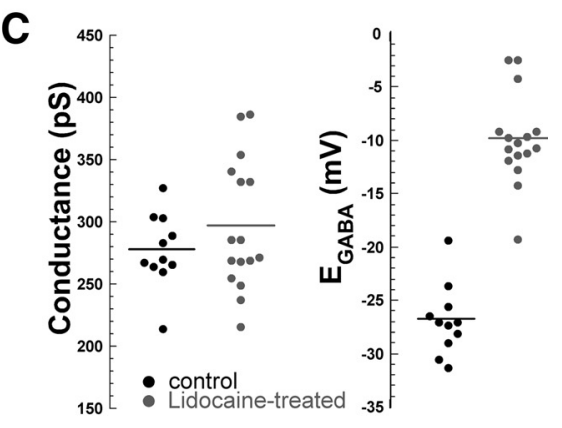

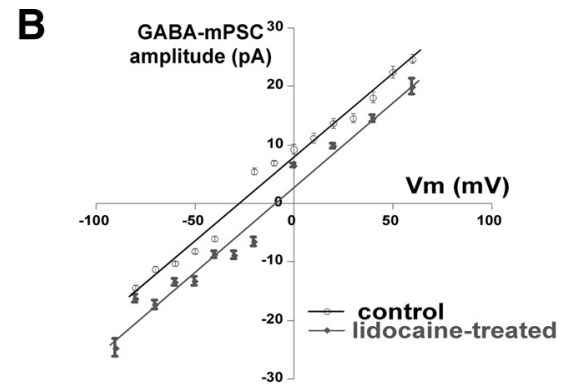
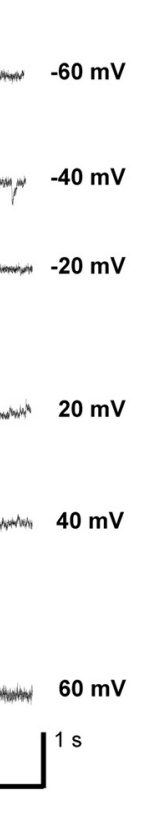

Figure 2. $\quad I_{\mathrm{mPSC}}-V$ plots from motoneurons show that GABAergic mPSC conductance was no different in control and treated embryos, while $E_{\mathrm{GABA}}$ was depolarized. $\boldsymbol{A}, \mathrm{mPSC}$ are shown at voltage steps of $20 \mathrm{mV}$ increments in a motoneuron from an activity-blocked embryo. $\boldsymbol{B}$, The average amplitude of GABAergic mPSCs at each step were then plotted against the step voltage. conductance (left) and reversal potentials (right) for several recorded cells (dots) from control (black) and activity-blocked (gray) erage values for cells.

moval of extracellular $\mathrm{HCO}_{3}^{-}$should significantly alter $E_{\mathrm{GABA}}$ if the permeability of the ion through the $\mathrm{GABA}_{\mathrm{A}}$ receptor had increased in activity-blocked embryos. Reducing $\mathrm{HCO}_{3}^{-}$produced a small hyperpolarization of $E_{\mathrm{GABA}}$ that was not significant $\left(E_{\mathrm{GABA}}\right.$ moved from $-8.8 \pm 2.8 \mathrm{mV}$ to $-12.5 \pm 3.0 \mathrm{mV}$ in the $0 \mathrm{mM} \mathrm{HCO}_{3}^{-}$solution, $n=4, p=0.38)$. Reducing $\mathrm{HCO}_{3}^{-}$did not significantly alter mPSC conductance $(339 \pm 21 \mathrm{pS}$ vs $314 \pm 14 \mathrm{pS}, n=4, p=0.13)$. This result is similar to the small shift in $E_{\mathrm{GABA}}$ that was reported for control embryos, and may result from the reduced function of the anion exchanger, AE3, which also contributes to chloride accumulation (Gonzalez-Islas et al., 2009). These results suggest that changes in $\mathrm{HCO}_{3}^{-}$permeability do not produce the depolarized shift in $E_{\mathrm{GABA}}$, but suggest that elevated intracellular chloride levels produce the scaling of $\mathrm{GABA}_{\mathrm{A}}$ mPSCs in activity-reduced embryos.

\section{Leak chloride current is not significantly reduced in lidocaine-treated embryos}

Elevated $\mathrm{Cl}_{\text {in }}^{-}$could occur through changes in the function of $\mathrm{Cl}^{-}$ transporters and/or through a reduction in $\mathrm{Cl}^{-}$leak currents. Tonically active $\mathrm{GABA}_{\mathrm{A}}$ receptors and other non-ligand-gated $\mathrm{Cl}^{-}$channels contribute to the total $\mathrm{Cl}^{-}$leak of the cell. To assess overall $\mathrm{Cl}^{-}$leak, we isolated these currents, to the extent possible in the isolated spinal preparation, by adding $\mathrm{K}^{+}, \mathrm{Ca}^{2+}, \mathrm{Na}^{+}$ channel blockers, glutamatergic receptor blockers, and replacing $\mathrm{K}^{+}$with $\mathrm{Cs}^{+}$in intracellular and extracellular solutions (see Materials and Methods). We then recorded whole cell from motoneurons and made voltage ramps from a holding potential of 0 $\mathrm{mV}$ to $-90 \mathrm{mV}$. To maintain stable intracellular $\mathrm{Cl}^{-}$levels at a holding potential of $0 \mathrm{mV}$, we set the chloride reversal potential near $0 \mathrm{mV}$ by using high concentrations of $\mathrm{Cl}^{-}$in the extracellular and patch solutions. This also provided the advantage that the $\mathrm{Cl}^{-}$leak current would have a significant driving force at voltages near the normal resting membrane potential, and could therefore be easily measured. Further, it was necessary to use high intracel- 


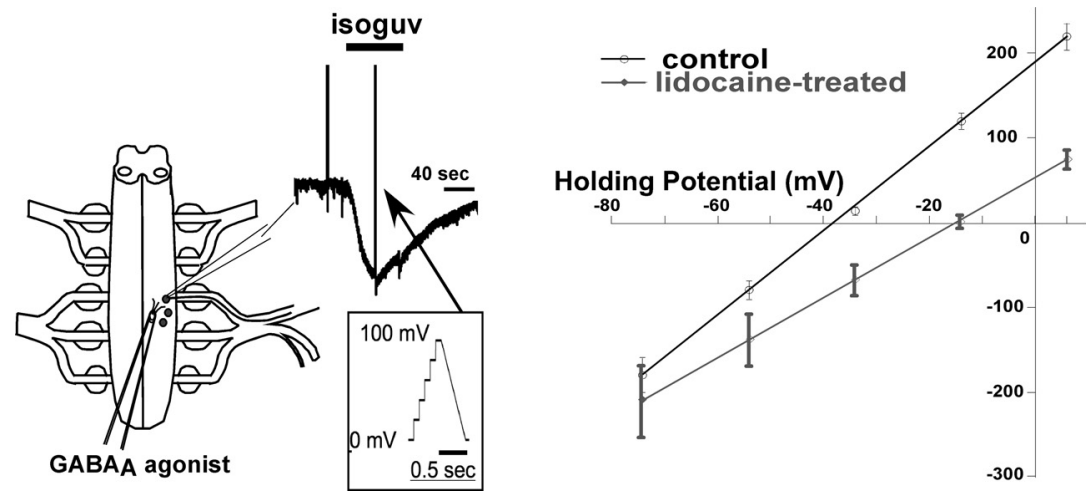

Figure 3. Perforated patch recordings show a depolarizing shift in GABAergic reversal potential in motoneurons from activityblocked embryos. Schematic shows puffing electrode adjacent to whole-cell recorded motoneuron. Trace shown of voltage-clamp recording using perforated patch electrode while picospritzing a $G_{A B A_{A}}$ agonist (isoguvacine, $-60 \mathrm{mV}$ ). Two voltage ramps are applied (one before and the other during agonist application). Box expands image of ramp, which is composed of upward steps followed by a downward ramp. GABAergic $I-V$ plots of control and activity-blocked motoneurons were generated by subtracting plots (isoguvacine - baseline). Plots are an average from 7 control and 7 activity-blocked embryos. Error bars represent SE.
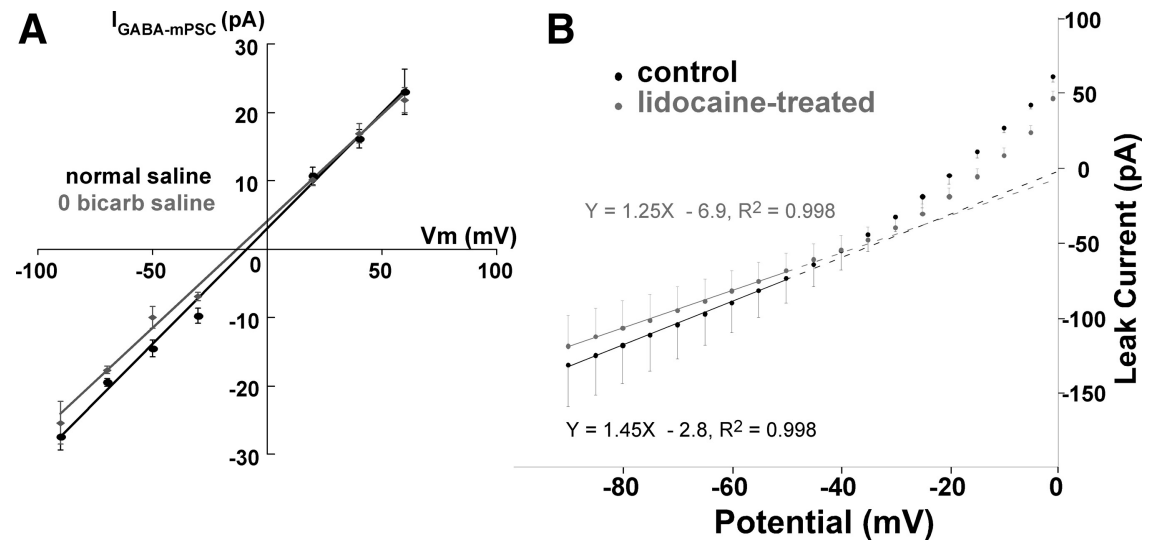

Figure 4. The shift in $E_{\mathrm{GABA}}$ was mediated by an increase in $\mathrm{Cl}^{-}$accumulation. $A$, The shift in $E_{\mathrm{GABA}}$ was not mediated by a change in $\mathrm{GABA}_{\mathrm{A}}$ receptor $\mathrm{HCO}_{3}^{-}$permeability. An $I_{\text {mPSC }}-V$ plot does not show significant shifts in $E_{\mathrm{GABA}}$ before and after perfusing a $0 \mathrm{~mm} \mathrm{HCO}_{3}^{-}$extracellular solution (average of 4 cells). $\boldsymbol{B}$, Enhanced $\mathrm{Cl}^{-}$accumulation in activity-blocked embryos was not due to changes in $\mathrm{Cl}^{-}$leak current. I-V plot constructed of a ramp from $0 \mathrm{mV}$ to $-90 \mathrm{mV}$. A linear fit of the data was made $(-50 \mathrm{to}-90$ $\mathrm{mV}) . \mathrm{Cl}^{-}$conductance was not significantly different in control and activity-blocked embryos. Equations for fitted lines are shown, and these lines are extended (dashed line) to approximate the currents reversal potential. Error bars represent SE.

lular patch $\mathrm{Cl}^{-}$to ensure that we set $\mathrm{Cl}_{\text {in }}^{-}$(Gonzalez-Islas et al., 2009). We then constructed $I-V$ plots to determine the conductance of the $\mathrm{Cl}^{-}$leak in control and lidocaine-treated motoneurons (Fig. $4 B$ ). We found a linear $I-V$ relationship when we fit values between $-90 \mathrm{mV}$ and $-50 \mathrm{mV}$ (Fig. $4 \mathrm{~B}$ ), typical of the resting membrane potential in these cells (Gonzalez-Islas and Wenner, 2006). Extension of the linear part of the fit allows us to approximate the reversal potential to $0 \mathrm{mV}$ (control $+1.9 \mathrm{mV}$, lidocaine treated $+5.5 \mathrm{mV}$ ), consistent with that expected for a chloride current. No significant difference $(p=0.72)$ in the conductance of the leak current could be detected in control ( $1.45 \pm 0.3$ $\mathrm{nS}, n=8)$ versus activity-blocked embryos (1.25 $\pm 0.2 \mathrm{nS}, n=8)$, consistent with the idea that changes in $\mathrm{Cl}^{-}$leak conductance did not underlie the greater $\mathrm{Cl}^{-}$accumulation of the lidocaine-treated embryos. An outward current was activated above $-40 \mathrm{mV}$, and we suspect this was a cesium-mediated current passing through incompletely blocked voltage-gated calcium channels (Hess et al., 1986). While we do not rule out the possibility there may also be a small reduction in conductance, it cannot account for the observed chloride accumulation in activity-blocked embryos. These results suggest that there is a positive shift in $E_{\mathrm{GABA}}$ that results from an increase in intracellular $\mathrm{Cl}^{-}$accumulation, but not through a reduction in the $\mathrm{Cl}^{-}$leak.

\section{Discussion}

Mechanisms underlying synaptic scaling have been studied almost exclusively following activity perturbations in vitro, and are thought to involve modifications that would change synaptic conductance. We show that $\mathrm{GABA}_{\mathrm{A}}$ mPSC conductance did not increase in activity-blocked embryonic motoneurons, demonstrating that there were no functional increases in postsynaptic receptors or vesicular transmitter concentration. In perforated patch recordings, we actually saw a slight reduction in the $\mathrm{GABA}_{\mathrm{A}}$ agonist-evoked conductance in lidocaine-treated motoneurons. This change in conductance may have resulted from a modification of the extrasynaptic $\mathrm{GABA}_{\mathrm{A}}$ receptor population. Instead, we find a novel intuitive mechanism for synaptic scaling in vivo, where GABAergic scaling was mediated by an increase in the driving force for chloride-mediated currents. $\mathrm{GABA}_{\mathrm{A}}$ mPSC amplitudes increase by $~ 50 \%$ following in ovo activity-block in embryonic motoneurons. We show that activity blockade triggered a $\sim 20 \mathrm{mV}$ depolarized shift in $E_{\mathrm{GABA}}$ using whole-cell and perforated patch recordings. The depolarized shift in $E_{\mathrm{GABA}}$ was mediated by increases in intracellular chloride; $\mathrm{HCO}_{3}^{-}$did not significantly influence $E_{\mathrm{GABA}}$ in control (Gonzalez-Islas et al., 2009) or lidocainetreated embryos (Fig. 4). Because $\mathrm{Cl}^{-}$leak current was no different in control and activity-blocked motoneurons, it is likely that there is an increase in chloride accumulation in embryonic motoneurons. NKCC1 is thought to accumulate chloride beyond its passive distribution resulting in depolarizing GABAergic responses in the early development of many neurons (Ben-Ari et al., 2007; Blaesse et al., 2009). In embryonic motoneurons both NKCC1 and the anion exchanger, AE3, have been shown to accumulate chloride (Chub et al., 2006; Delpy et al., 2008; Vinay and Jean-Xavier, 2008; Gonzalez-Islas et al., 2009), and are therefore likely candidates for mediating the enhanced $\mathrm{Cl}_{\text {in }}^{-}$in activity-blocked motoneurons.

Recent work has raised the possibility that the depolarized nature of GABA, and the resulting spontaneous network activity observed in vitro in neonatal brain slices were a consequence of saline solutions that were deficient in energy substrates, such as ketone bodies (Rheims et al., 2009; Holmgren et al., 2010). It is highly unlikely that neurons of the isolated embryonic spinal cord exhibit depolarizing GABAergic transmission or SNA due to a deficiency in energy substrates of the saline solution. First, spinal SNA recorded in vitro is quite similar to SNA recorded in ovo, as determined by EMG recordings (Landmesser and O'Donovan, 1984; O'Donovan et al., 1998). Second, blockade of GABA $\mathrm{A}$ receptors in vivo (injection of gabazine or bicuculline in ovo) blocks embryonic movements suggesting GABAergic currents are likely 
to be depolarizing in the living embryo (Wilhelm and Wenner, 2008).

Synaptic scaling of GABAergic mPSCs was demonstrated in visual cortical cells in culture, but was not dependent on changes in chloride reversal potential (Kilman et al., 2002). The distinct mechanisms underlying GABAergic scaling in embryonic motoneurons where GABA is excitatory, and cultured cells where GABA is inhibitory could be due to the difference in developmental stages. On the other hand, another study using hippocampal cultures, where GABA was inhibitory, suggested the possibility that inhibitory reversal potential had changed as a compensation to activity blockade, although quantal amplitude was not assessed and $E_{\mathrm{GABA}}$ was not directly measured (Karmarkar and Buonomano, 2006). Several other studies have described fast forms of GABAergic synaptic plasticity, involving shifts in $E_{\mathrm{GABA}}$ through changes in the function of $\mathrm{Cl}^{-}$transporters, although these forms of plasticity are distinct from homeostatic plasticity (Fiumelli and Woodin, 2007; Xu et al., 2008; Yang et al., 2010).

It is becoming clear that the nervous system modulates the strength of inhibition through changes in the regulation of intracellular chloride both in development when intracellular chloride levels are high, and in mature neurons following injury or disease where low chloride levels are increased toward developmental concentrations (Ben-Ari et al., 2007; Fiumelli and Woodin, 2007; Blaesse et al., 2009). Spinal cord injury, nerve injury, traumatic brain injury, axotomy, and ischemia all lead to a pathophysiology that results from a depolarization of $E_{\mathrm{GABA}}$ via chloride accumulation (Ben-Ari et al., 2007; De Koninck, 2007; Blaesse et al., 2009; Boulenguez et al., 2010). We have observed a similar response following activity blockade, as a homeostatic mechanism of GABAergic synaptic scaling. It is therefore tempting to speculate that injury-induced increases in chloride accumulation may be caused by alterations in network activity that trigger homeostatic plasticity mechanisms.

We have previously demonstrated that reduced $\mathrm{GABA}_{\mathrm{A}}$ transmission triggers homeostatic changes in synaptic scaling and cellular excitability (Wilhelm and Wenner, 2008; Wilhelm et al., 2009). It will therefore be important in future studies to determine whether shifts in $E_{\mathrm{Cl}}$ are triggered by $\mathrm{GABA}_{\mathrm{A}}$ blockade.

\section{References}

Ben-Ari Y (2001) Developing networks play a similar melody. Trends Neurosci 24:353-360.

Ben-Ari Y, Gaiarsa JL, Tyzio R, Khazipov R (2007) GABA: a pioneer transmitter that excites immature neurons and generates primitive oscillations. Physiol Rev 87:1215-1284.

Blaesse P, Airaksinen MS, Rivera C, Kaila K (2009) Cation-chloride cotransporters and neuronal function. Neuron 61:820-838.

Boulenguez P, Liabeuf S, Bos R, Bras H, Jean-Xavier C, Brocard C, Stil A, Darbon P, Cattaert D, Delpire E, Marsala M, Vinay L (2010) Downregulation of the potassium-chloride cotransporter KCC2 contributes to spasticity after spinal cord injury. Nat Med 16:302-307.

Chub N, O’Donovan MJ (2001) Post-episode depression of GABAergic transmission in spinal neurons of the chick embryo. J Neurophysiol 85: 2166-2176.

Chub N, Mentis GZ, O’Donovan MJ (2006) Chloride-sensitive MEQ fluorescence in chick embryo motoneurons following manipulations of chloride and during spontaneous network activity. J Neurophysiol 95:323-330.

De Koninck Y (2007) Altered chloride homeostasis in neurological disorders: a new target. Curr Opin Pharmacol 7:93-99.

Delpy A, Allain AE, Meyrand P, Branchereau P (2008) NKCC1 cotrans- porter inactivation underlies embryonic development of chloridemediated inhibition in mouse spinal motoneuron. J Physiol 586: 1059-1075.

Fiumelli H, Woodin MA (2007) Role of activity-dependent regulation of neuronal chloride homeostasis in development. Curr Opin Neurobiol 17:81-86.

Gonzalez-Islas C, Wenner P (2006) Spontaneous network activity in the embryonic spinal cord regulates AMPAergic and GABAergic synaptic strength. Neuron 49:563-575.

Gonzalez-Islas C, Chub N, Wenner P (2009) NKCC1 and AE3 appear to accumulate chloride in embryonic motoneurons. J Neurophysiol 101: 507-518.

Hamburger V, Hamilton HL (1951) A series of normal stages in the development of the normal chick embryo. J Morphol 88:49-92.

Hess P, Lansman JB, Tsien RW (1986) Calcium channel selectivity for divalent and monovalent cations. Voltage and concentration dependence of single channel current in ventricular heart cells. J Gen Physiol 88:293-319.

Holmgren CD, Mukhtarov M, Malkov AE, Popova IY, Bregestovski P, Zilberter Y (2010) Energy substrate availability as a determinant of neuronal resting potential, GABA signaling and spontaneous network activity in the neonatal cortex in vitro. J Neurochem 112:900-912.

Karmarkar UR, Buonomano DV (2006) Different forms of homeostatic plasticity are engaged with distinct temporal profiles. Eur J Neurosci 23:1575-1584.

Kilman V, van Rossum MC, Turrigiano GG (2002) Activity deprivation reduces miniature IPSC amplitude by decreasing the number of postsynaptic $\mathrm{GABA}_{\mathrm{A}}$ receptors clustered at neocortical synapses. J Neurosci 22:1328-1337.

Landmesser LT, O’Donovan MJ (1984) Activation patterns of embryonic chick hind limb muscles recorded in ovo and in an isolated spinal cord preparation. J Physiol 347:189-204.

O'Donovan MJ (1999) The origin of spontaneous activity in developing networks of the vertebrate nervous system. Curr Opin Neurobiol 9:94-104

O’Donovan MJ, Chub N, Wenner P (1998) Mechanisms of spontaneous activity in developing spinal networks. J Neurobiol 37:131-145.

Rheims S, Holmgren CD, Chazal G, Mulder J, Harkany T, Zilberter T, Zilberter Y (2009) GABA action in immature neocortical neurons directly depends on the availability of ketone bodies. J Neurochem 110:1330-1338.

Rich MM, Wenner P (2007) Sensing and expressing homeostatic synaptic plasticity. Trends Neurosci 30:119-125.

Turrigiano GG (2008) The self-tuning neuron: synaptic scaling of excitatory synapses. Cell 135:422-435.

Turrigiano GG, Leslie KR, Desai NS, Rutherford LC, Nelson SB (1998) Activity-dependent scaling of quantal amplitude in neocortical neurons. Nature 391:892-896.

Vinay L, Jean-Xavier C (2008) Plasticity of spinal cord locomotor networks and contribution of cation-chloride cotransporters. Brain Res Rev 57: $103-110$.

Wilhelm JC, Wenner P (2008) GABAA transmission is a critical step in the process of triggering homeostatic increases in quantal amplitude. Proc Natl Acad Sci U S A 105:11412-11417.

Wilhelm JC, Rich MM, Wenner P (2009) Compensatory changes in cellular excitability, not synaptic scaling, contribute to homeostatic recovery of embryonic network activity. Proc Natl Acad Sci U S A 106:6760-6765.

Wilson NR, Kang J, Hueske EV, Leung T, Varoqui H, Murnick JG, Erickson JD, Liu G (2005) Presynaptic regulation of quantal size by the vesicular glutamate transporter VGLUT1. J Neurosci 25:6221-6234.

Xu C, Zhao MX, Poo MM, Zhang XH (2008) GABA(B) receptor activation mediates frequency-dependent plasticity of developing GABAergic synapses. Nat Neurosci 11:1410-1418.

Yang B, Tadavarty R, Xu JY, Sastry BR (2010) Activity-mediated plasticity of GABA equilibrium potential in rat hippocampal CA1 neurons. Exp Neurol 221:157-165.

Zhang LI, Poo MM (2001) Electrical activity and development of neural circuits. Nat Neurosci 4 [Suppl]:S1207-S1214. 